\title{
A doutrina do adimplemento substancial no Direito brasileiro e em perspectiva comparativista
}

\section{Anelise Becker}

Mestranda em Direito Civil na

Universidade Federal do Rio Grande do Sul.

\section{SUMÁRIO}

Introdução. Parte I. Origem: A doutrina da substancial performance. A) Condition e Warranty; B) Substancial Performance. B.1. Parâmetros para a aplicação judicial da doutrina; B.2. Efeitos. Parte II. A recepção da doutrina nos países da Civil Law. A) O adimplemento substancial em perspectiva comparativista e no direito internacional; B) O adimplemento substancial no direito brasileiro. B.1. A base legal para sua aplicação; B.2. A atuação do princípio da boa fé objetiva; B.3. Soluçōes jurisprudenciais. Conclusão.

\section{Introdução}

Tratar da doutrina do adimplemento substancial significa trazer à discussão grande parte das proposições do moderno Direito Obrigacional: o conceito de obrigação como processo ${ }^{1}$, o princípio da boa fé como reflexo do fenômeno geral de eticização jurídica $^{2}$ - como limitador do princípio da autonomia da vontade -, a funcionalização dos direitos de crédito operada por meio da figura do abuso de direito, a relevância atribuída ao interesse também do devedor $e$ ainda, a teoria da causa, compreendida no sentido que lhe dá a doutrina italiana, i. é, a causa como função econômico-social do contrato ${ }^{3}$.

Uma vez inserindo-se a problemática do adimplemento substancial na questão da funcionalização dos direitos de crédito, está-se tocando na teoria da causa como a função econômico-social daquele direito. Nesta perspectiva, a compreensão e aplicação da doutrina do adimplemento substancial imbrica-se com o exame da causa para saber se, na relação obrigacional concreta, esta foi, ou não, atingida.

A relação obrigacional complexa é vista como uma ordem de cooperasáa recíproca entre credor e devedor, polarizada pelo adimplemento, cujo escopo é a satisfação dos interesses do credor ${ }^{4}$. Assim é definida porque, em razão

$$
\text { R. Fac. Direito UFRGS, Porto Alegre, 9(1): 60-77, nov. } 1993
$$

de vez que aquela primeira pretensão viria ferir o princípio da boa fé.

Para bem compreendê-lo, principalmente naquelas legislações que utilizam a expressão inadimplemento de escassa importância"8, é importante observar a relação que há entre um "inadimplemento fundamental" e um "adimplemento substancial".

Quando o inadimplemento é fundamental. o essencial da prestação não foi cumprido, pelo que, não foram atendidos os interesses do credor, facultando-se-lhe a resolução do negócio. Neste caso, esta é legítima porque ele se estará protegendo da possibilidade de, adimplindo integralmente, ver-se privado da contraprestação, o que comprometeria a economia do contrato e ensejaria o enriquecimento ilícito do devedor inadimplente.

De outro lado, quando o adimplemento é substancial, foi cumprido aquilo que era essencial na relação obrigacional e, por isso, satisfeitos os interesses do credor. Não estaria este, portanto, defendendo qualquer in teresse legítimo ao pedir sua resolução em virtude do descumprimento de detalhes secundários, que não interfere no proveito que tira da prestação efetivamente oferecida. Outorga-se-lhe o direito a perdas e danos para que se mantenha o equilíbrio contratual, ao compensarem-se as diferenças ou prejuízos relativos à prestação imperfeita $\mathrm{e}$ se possível, o pedido de adimplemento.

Com vistas a um melhor entendimento destas questões, de certa forma ainda pouco tratadas entre nós - inobstante seu inegável interesse prático - é necessário que se examine, inicialmente, a origem da teoria, a substancial performance do direito anglo-americano. Num segundo momento, será interessante observar sua recepção e manifestação em alguns sistemas da chamada $c i$ vil law, bem como sua atuação no direito internacional, para realizar, por fim, a sua apreciação à luz do Direito brasileiro.

Parte I. Origem: A doutrina da substancial performance

Antes de tratar-se propriamente da doutrina da substancial performance, é importan- te a consideração preliminar da distinção entre os conceitos de condition e warranty, pois foi com base neste discrime que surgiu a referida doutrina.

\section{A. Condition e Warranty}

A doutrina da substancial performance foi elaborada na Inglaterra, no século XVIII, com o caso Boone v. Eyre, de 1.779 , tendo por base uma distinção que se fazia na época entre os tipos de cláusulas que os contratos poderiam conter e as respectivas conseqüências, de diferentes graus de gravidade, que poderiam advir da infração de uma ou outra.

Lord Mansfield, que julgou o caso Boone v. Eyre, distinguia, em um contrato, obrigações dependentes (conditions) e obrigações independentes ${ }^{9}$. As primeiras tinham o sentido de "interdependentes", significando que estavam indissoluvelmente ligadas a todas as obrigações correlativas do co-contratante (sentido clássico da consideration ${ }^{10}$ ). Já as obrigações chamadas independentes escapariam à reciprocidade contratual, de vez que acessórias, secundários. Sua inexecução restaria sem efeito sobre o direito de exigir as prestações prometidas pela outra parte e, por conseguinte, não lhes poderia ser oposta uma exceção de não cumprimento, eximindo-se a parte de pagar-lhe o preço.

O caso é bastante elucidativo: o demandante, Boone, obrigara-se a transferir ao demandado, Eyre, a propriedade de uma plantação nas Antilhas, com os escravos que ali viviam. Garantia ao adquirente seu domínio e posse pacíficos. Em contrapartida (consideration), Eyre obrigara-se a pagar-lhe 500 libras e uma renda anual de 160 libras. Em juízo, Boone cobrava-lhe o pagamento de 400 libras de renda atrasada e Eyre alegava que Boone não havia executado a obrigação de garantir-lhe o domínio sobre os bens alienados, pois a plantação the pertencia por hora da conclusão do contrato, mas não mais os escravos. Lord Mansfield entendeu que esta inexecução não dispensava o comprador da obrigação de pagar o preço e a ação foi julgada procedente. 
Conforme Lord Mansfield ${ }^{11}$, tal não configurava uma obrigação dependente (condition), mas uma obrigação secundária, cuja inexecução se resolveria em perdas e danos e não levaria à ruptura do contrato: "A distinção é muito clara; se as estipulações recíprocas concernem à totalidade da consi deration de parte a parte, são conditions mútuas e cada qual tem o efeito de suspender a outra. Ao contrário, se concernem somente a uma parte da consideration, a inexecução pode ser reparada por perdas e danos"12.

Modernamente, tal distinção transformou-se na oposição entre conditions e warranties. As conditions são cláusulas essenciais, constituindo a própria substância do con trato, cujo cumprimento é imprescindível manutenção do sinalagma. As warranties, por sua vez, correspondendo àquelas "obrigações independentes", estão em uma segun da ordem de importância e seu descumprimento, portanto, não afeta o equilíbrio contratual (consideration).

Cabia às partes determinarem no contrato o que configuraria uma condition e su vontade seria lei para os juízes em virtude do princípio da autonomia da vontade.

Violada uma condition, atingido seria equilíbrio contratual. À parte lesada caberia, então, pedir a sua resolução, com o que, a parte inadimplente nada lhe poderia exigir, ainda que houvesse prestado algo.

Caso a infração fosse a uma warranty, relação contratual não seria discutida e o contratante não inadimplente estaria legitimado apenas a pedir o adimplemento do que fora omitido, se possível, e o ressarcimento dos danos sofridos.

Hoje, no entanto, a tradicional distinção entre cláusulas conditions e cláusulas warranties é apenas um dos parâmetros, e não o exclusivo, para determinar o grau de importância do inadimplemento. A tendênci atual da jurisprudência inglesa é no sentido de adotar como critério geral, para fins de resolução do contrato ${ }^{13}$, a própria base da distinção, que tem caráter estritamente objetivo. Trata-se de verificar se o inadimplemento é ou não fundamental (fundamental breach $\left.{ }^{14}\right)$. Conseqüentemente, está-se dando 62 maior poder de apreciação para o julgador. Uma vez que o critério é objetivo, ele não mais estará vinculado tão estritamente às estipulações contratuais acerca do que seja ou não condition: verificará a relação de fato entre o adimplido e a totalidade da prestação, embora seja aconselhável, para tanto, além de aferir a seriedade das conseqüências que de fato resultaram do descumprimento, verificar, também, a importância que as partes "pareceram dar" à cláusula infringida ${ }^{15}$

Se o inadimplemento de um dos contratantes constituir uma fundamental breach, o outro poderá resolver o contrato, do mesmo modo como se se tratasse de um inadimplemento total. Do contrário, as conseqüências serão as de um adimplemento substancial.

\section{B. Substancial performance}

Vige na Common Law a regra segundo a qual o credor pode recusar um pagamento parcial ou que não corresponda aos termos do contrato. Por conseguinte, o adimplemento deve ser integral para que a parte possa reclamar a contraprestação.

A aplicação desta regra, em rigoroso formalismo, levou a muitas decisões iníquas, como a do caso Cutter v Pozell, de $1.795^{16}$.

Cutter partiu em 02 de agosto de 1.793 de Kingston, Jamaica, como imediato do navio, em viagem para Liverpool, que terminaria em 09 de outubro seguinte. Mas em 20 de setembro, Cutter morreu a bordo, em pleno mar. Sua viúva postulou em juízo o valor que the seria devido pelo trabatho prestado a bordo. Foi decidido que ela não teria direito a nenhum salário, nem mesmo pelo período durante o qual Cutter trabalhara, i. é, de 02 de agosto a 20 de setembro, pois o Tribunal entendeu não haver Cutter executado a obrigação de servir, como imediato, de Kingston a Liverpool. Tendo sido estipulado que sua remuneração seria pelo total da viagem, completá-la representava condition para seu pagamento.

Este tipo de decisão, evidentemente injusta, cedo foi diagnosticado pelas Cortes da Equity que, estabelecendo a doutrina da substancial performance, possibilitaram deci- sões mais conformes às exigências do princípio da boa fé objetiva.

Começou-se a cogitar, então, da gravidade do incumprimento para efeitos de outorga da resolução, como forma de proteger contraparte. E a noção de substancial perfo mance surgiu da inversão do ponto de vista do julgador que, de apreciar a gravidade partir da inexecução, passou a considerar a execução, a fim determinar se ela satisfazia em substância a totalidade das obrigações estipuladas, apesar de sua imperfeição"

Aplicada esta doutrina, aquele contratante que prestou de forma quase exata (mas não exata) não mais perderia o direito de reclamar o preço, como ocorria por força da referida regra da Common Law. Se o seur adimplemento tivesse sido substancial, ainda que imperfeito, teria direito à contraprestação, resguardado o direito do credor em exigir-lhe o ressarcimento dos prejuízos causados pela imperfeição e/ou a parte faltante $\mathrm{Um}$ desvio insignificante do que fora estipulado no contrato não mais justificaria su resolução e a conseqüente perda de toda contraprestação por parte daquele que adimpliu inexata, mas substancialmente.

$\mathrm{Na}$ verdade, por não permitir que um dos contratantes se beneficie de uma ligeira desconformidade entre a prestação e o contratado para pretender considerá-la um pagamento parcial, passível de recusa, autorizando-o, portanto, a não executar suas próprias obrigações, a doutrina do adimple mento substancial é uma forma de preven ção ao enriquecimento ilícito. Talvez po isso Cheshire e Fifoots ${ }^{18}$ considerem-n mais uma qualificação do que uma exceção à regra que exige o cumprimento estrito.

Com a reforma judiciária de 1.873 , estabeleceu-se que, em caso de conflito, prevaleceriam as regras da Equity sobre as da Common Law, com o que, a doutrina da substancial performance passa a ter maior expressão ${ }^{19}$

Resta-nos examinar como se dá a sua aplicação pelos tribunais: as circunstância cuja presença se exige para que se considere um contrato substancialmente cumprido as conseqüências que daí se seguem.
B.1. Parâmetros para a aplicação judicial da doutrina

Não existe uma fórmula fixa para determinar o que seja o adimplemento substancial de um contrato. Cabe ao julgador, face às circunstâncias do caso concreto, pesar a gravidade do descumprimento e o grau de satisfação dos interesses do credor. Isto implica em um alargamento dos limites do poder judicial na apreciação do caso concreto, o que, por sua vez, pressupõe uma mudança no próprio método de aplicação do direito ou seja, a superação do raciocínio lógicosubsuntivo pelo da concreção ${ }^{20}$. Apenas este último método, que utiliza parâmetros concretos para a solução de casos concretos, admite um tipo de construção jurisprudencial como o da doutrina do adimplemento substancial. Decorre daí a necessidade de apuraremse cada vez mais tais parâmetros (standards) pois eles serão os limites para o julgador.

Por esta razão, tem grande utilidade para nós a experiência dos tribunais ingleses e norte-americanos. Examinando-se numerosas decisões ${ }^{21}$, é possível concluir que se fazem necessárias três circunstâncias para que determinado adimplemento possa ser considerado como substancial. A primeira delas é a proximidade entre o efetivamente realizado e aquilo que estava previsto no contrato. A segunda, é que a prestação imperfeita satisfaça os interesses do credor. A terceira (questionável se considerar-se o adimplemento substancial apenas sob uma ótica objetivista) refere-se ao esforço, diligência do devedor em adimplir integralmente.

a) Insignificância do inadimplemento

$\mathrm{O}$ adimplemento substancial consiste em um resultado tão próximo do almejado, que não chega a abalar a reciprocidade, o sinalagma das prestações correspectivas. Por isso mantém-se o contrato, concedendo-se ao credor direito a ser ressarcido pelos de feitos da prestação, porque o prejuízo, ainda que secundário, se existe, deve ser reparado ${ }^{22}$

A avaliação da insignificância dos defeitos ou omissões deve ter por referência contrato como um todo, e não as suas par- 
tes consideradas isoladamente. É possível que toda uma parte tenha sido omitida, mas se ela, face à totalidade do contratado, não representar uma falha significativa, fundamental, não poderá haver resolução ${ }^{23}$

Os defeitos não podem constituir um desvio no plano geral tencionado para trabalho e nem ser tão essenciais que objetivo das partes em fazer o contrato seus propósitos não possam, sem dificulda$\mathrm{de}$, ser realizados remediando-os ${ }^{24}$. Aqui se acena para o critério subjetivo segundo qual é grave o inadimplemento que, acaso previsto pelo credor por hora da celebração do contrato, desestimular-lhe-ia a contratação.

Deve haver tal aproximação com a "performance contratual" completa, de modo que o credor receba, substancialmente, aquilo a que visava com o contrato, embora poss não ser o mesmo em cada particular e em bora possam haver omissões e imperfeições à conta das quais poderá haver uma redução no preço do contrato ${ }^{25}$. A prestação deve ser, ainda, adequada ao fim para o qual for designada: pode ser inexata, mas não um aliud. No entanto, pesa mais a inadequação, pois torna a coisa inútil, do que propria mente a falta de identidade ${ }^{26}$.

É necessário, entretanto, cautela ao permitirem-se tais desvios ${ }^{27}$. Trata-se de atende também à expectativa do credor e não só utilidade da prestação, como no caso de quem adquire um vestido de estilista famoso. Esta pessoa tem a expectativa de ser única a possuir tal modelo, não bastando portanto, que a peça lhe seja apenas útil: há que ser também exclusiva.

Quando as partes convencionam que objeto da prestação deverá ser conforme um determinado modelo, não lhes é razoáve pretender que ambos devam ser precisamente iguais em todos os ínfimos detalhes, que não possa haver a menor diferença entre eles, ainda que sem importância ${ }^{28}$. Trata-se aqui de mais uma manifestação do princí pio da boa fé objetiva, no sentido da "extensión que se le concede al juez en caso de insignificancia: minima non curat praetor ${ }^{\prime 29}$, porque, na maior parte das vezes, a invocação de algo mínimo traduz um "ejercicio 64 claramente inicuo del derecho", face à desproporção entre os interesses envolvidos ${ }^{30}$.

\section{b) Satisfação do interesse do credor}

Se o inadimplemento é insignificante, entre o benefício efetivamente concedido ao credor e aquele que pretendia obter por meio do contrato, não haverá realmente diferença. Os eventuais prejuízos serão cobertos através do ressarcimento compatível. "Onde a parte recebeu substancialmente o benefício que esperava, embora as condições do contrato tenham sido descumpridas em particulares insignificantes, que não lhe tiram o benefício que iria obter com o cumprimento literal, ela é obrigada a pagar o preço sob a doutrina do adimplemento substancial ${ }^{131}$. Forte indício de que a prestação defeituosa é suficiente para atender aos interesses do credor é a sua retenção por $e^{e s t e}{ }^{32}$. Por outro lado, o dever de diligência a cargo do credor pode levar a considerar sanadas as deficiências ou irregularidades da prestação, contra as quais não reagiu oportunamente, podendo e devendo tê-lo feito ${ }^{33}$

Entretanto, mesmo que ínfimo o descumprimento, conforme o caso, poderá representar perda total do interesse do credor pela prestação defeituosa, justificando-se a resolução. Quando alguém encomenda um buffet para ser servido em uma festa marcada para as vinte horas, se o é à meia-noite, o atraso - que se outro fosse o tipo da prestação, seria irrisório -, neste caso, tornou-a inútil, porque a hora aprazada é componente vital do interesse do credor $^{34}$. Assim, a diferença de apenas quatro horas no cumprimento da prestação, o que, a rigor, é algo ínfimo, despiu-a de utilidade para o credor, com o que, justifica-se a resolução ${ }^{35}$. Mesmo que mínima a desconformidade, na hipótese não se poderá falar, portanto, em adimplemento substancial, eis que carecedora a prestação de interesse para o credor. Decisivo é, sempre, o atendimento do interesse do credor.

\section{c) Diligência por parte do devedor}

Em vista da incidência do princípio da boa fé objetiva, as partes, tanto na consti- tuição como no desenvolvimento do vínculo obrigacional, devem agir conforme a boa fé, ou seja, com correção, respeito, buscando ao máximo a satisfação dos interesses do co-contratante, evitando causar-lhe danos. Pode-se dizer, então, que as obrigações devem ser cumpridas segundo a boa $\mathrm{fe}^{36}$. Isto, entre outros, importa em dever de diligência ${ }^{37}$ para o devedor, que é o que aqui nos interessa.

Tal dever impõe-lhe "o adequado esforço volitivo e técnico para realizar o interesse do credor e não lesar direitos alheios. (...) Para satisfazer ou respeitar tais interesses, deve o sujeito lançar mão de todo o esforço apropriado, segundo um critério de normalidade, empregando meios materiais, observando normas técnicas e jurídicas, adotando a cautela adequada, etc ${ }^{1138}$.

Considerando-se a verificação da substancialidade do adimplemento algo de ordem estritamente objetiva, o esforço, a diligência do devedor são irrelevantes. Mesmo se agiu negligente ou propositadamente no sentido de deixar a obra incompleta, se esta, ainda assim satisfaz ao credor, estar-lhe-á vedada a resolução.

É importante, no entanto, ter-se em vista também o aspecto subjetivo. $\mathrm{Na}$ Equity, origem da doutrina, vige a máxima "must come into equity with clean hands". Ao ser aplicada através do princípio da boa fé objetiva, o dever de diligência também não poderia ser afastado, porque intimamente vinculado a tal princípio. Parece mais conveniente, porém, deixar a cargo do julgador, frente às circunstâncias do caso concreto, a decisão acerca da necessidade ou não de exigir tal conduta, para permitir-lhe fazer justiça, o que, afinal, é o objetivo maior, Muitas vezes, ainda que o devedor não se tenha esforçado devidamente em cumprir o contrato com exatidão, poderá ser ainda mais injusto resolvê-lo se efetivamente satisfeito o interesse do credor $^{39}$.

Para a jurisprudência norte-americana, é importante a conduta do devedor; é dito que "a doutrina da substancial performance pretende a proteção e auxílio daqueles que leal e honestamente esforçaram-se em executar seus contratos em todos os particulares materiais e substanciais, de modo que seu direito à compensação não deva ser perdido em razão de meros defeitos ou omissões técnicas, inadvertidas ou não importan-

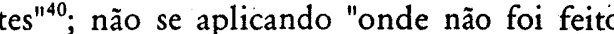
real esforço para cumprir com o contrato" ${ }^{141}$.

Assim, há um adimplemento substancial onde a variação das especificações do contrato é pouco importante, de modo que prestação realmente oferecida é, substancialmente, aquela estipulada no contrato e então pode ser usada (e o é) para o propósito pretendido; onde os defeitos podem ser sanados sem grande despesa e sem dano material em outras partes da obra, podendo ser compensados sem injustiça com deduções no preço do contrato e, conforme o caso, onde seja evidente que o devedor se esforçou para adimplir integralmente ${ }^{42}$. Resulta daí que o contrato não poderá ser resolvido.

Cabe, no entanto, melhor indicar a extensão das conseqüências, ou efeitos, da aplicação da doutrina.

\section{B.2. Efeitos}

a) A manutenção da relação contratual

O direito de resolução é um direito formativo extintivo ${ }^{43}$. Seu fundamento está na destruição da relação de reciprocidade, no rompimento do equilíbrio contratual, que faz com que as partes de um contrato oneroso não mais possam lograr o fim econômico-social por elas visado.

$O$ inadimplemento ou o adimplemento inútil são causas de desequilíbrio porque privam uma das partes da contraprestação a que tem direito. Por isso se lhe concede o direito de resolução, como medida preventiva ${ }^{44}$.

Mas, para que haja efetivamente um desequilíbrio, algo que pese na reciprocidade das prestações, é necessário que tal inadimplemento seja significativo a ponto de privar substancialmente o credor da prestação a que teria direito - não se pode tratar portanto, simplesmente de falha secundária, sem reflexo na economia contratual.

No caso de adimplemento substancial, há um adimplemento bom o suficiente para satisfazer o interesse do credor, pelo que, 
não há comprometimento da comutatividade. Haverá, isto sim, com a resolução. Eventuais diferenças serão remediadas através de indenização. Não há falar-se, portanto, em resolução, tampouco em exceção de contrato não cumprido, eis que, nestas circunstâncias, carecem de fundamento.

\section{b) Perdas e danos}

Cabe o ressarcimento das perdas e dano sofridas pelo credor em razão do adimplemento inexato porque, afinal, "a parte inadimplente nunca pode lucrar por sua inadimplência e à outra nunca pode se permitido perder por isso"45.

Esse ressarcimento pode-se dar através de compensação, se a contraprestação divisível ainda não foi realizada ou, se já o foi ou for indivisível, mediante o pagamento de quantia suficiente para a reequiparação.

Em ambos os casos, não estará adstrito à diferença entre o preço estipulado no contrato e o valor real da prestação defeituosa, podendo abranger todas as perdas e danos suplementares em vista das despesas realizadas na sua reparação ${ }^{46}$. É a questão do agravamento do prejuízo, sujeito, entretanto, às ressalvas da doctrine of mitigation, segundo a qual o credor deve cooperar no sentido de não agravar o resultado danoso decorrente do não cumprimento por injustificada ação ou omissão sua ${ }^{47}$. Do mesmo modo, se a gravidade do inadimplemento se deveu a fato do credor, não poderá legitimar pedido de resolução ${ }^{48}$.

\section{c) Pedido de adimplemento}

Cabe ao credor, independentemente do ressarcimento dos prejuízos sofridos em razão do cumprimento inexato, o pedido de adimplemento da parte faltante, se tal for possível.

Parte II. A Recepção da doutrina do adimplemento substancial nos países da civil law

Em diversos sistemas jurídicos, expressa previsão legal estabelece que apenas será possível a resolução do contrato na hipótese 66 de ser grave o inadimplemento; ou seja, em sendo ele de pouca importância, não haverá direito à resolução. Disto se pode inferir que, se de pouca importância o inadimplemento, substancial o adimplemento, pelo que, aberta está a via de aplicação desta doutrina.

Em razão da diversidade entre o Direito do sistema da Common Law e o dos países do sistema romano-germânico, é importante para nós o estudo das manifestações da doutrina do adimplemento substancial, ainda que não nominadamente, em alguns deles. Isto nos fornece elementos que facilitam sua aplicação em nosso Direito.

Num primeiro momento, faremos uma breve incursão pelos Direitos italiano, português, francês, alemão, espanhol e argentino e, no plano de Direito Internacional, pela Convenção de Viena. A seguir, trataremos, mais detidamente, da aplicação da doutrina no Direito brasileiro.

\section{A. O adimplemento substancial em} perspectiva comparativista e no direito internaciona

Estabelece o artigo 1.455 dó Código Civil Italiano que o contrato não pode ser resolvido se o inadimplemento de uma das partes tem escassa importância, resguardado o interesse da outra ${ }^{49}$

Cabe ao juiz, com fundamento neste artigo, e utilizando um critério de boa fé objetiva, verificar a gravidade do inadimplemento e o interesse concreto do co-contratante na exata e tempestiva prestação. Se este ainda se mantém na prestação defeituosa, não terá sido grave o inadimplemento. Somente o será aquele que turbar sensivelmente o equilíbrio contratual, de modo a fazer com que a parte não inadimplente sofra sacrifício além do limite razoável, dos riscos inerentes ao negócio ${ }^{50}$

Se o caso concreto é de adimplemento substancial (por ter sido satisfeita a substância da prestação), não há, é claro, comprometimento do sinalagma e, para ter sido reconhecido como substancial, apresenta interesse para o credor assim como foi execu- tado. Desta forma, está-se diante do inadempimento de scarsa importanza, que veda o pedido de resolução no Direito italiano.

No Direito português, o artigo $802, \mathrm{n}^{\circ} 2$, do Código Civil, exerce função semelhante. De acordo com o referido artigo, o credor não pode resolver o negócio se o não cumprimento parcial, atendendo ao seu interesse, tiver escassa importância.

E possível que também o artigo 1.184 do Código Civil Francês, por meio da atividade jurisprudencial, possa produzir efeitos semelhantes aos da doutrina do adimplemento substancial. Esta regra permite ao juiz beneficiar o devedor inadimplente com uma dilatação do prazo contratual. Mas a jurisprudência francesa também exercita este poder em caso de inexecução parcial ou de pouca gravidade que proporcione ao credor o benefício essencial do contrato, no sentido de declarar a manutenção do contrato, rejeitando o pedido resolutivo, mediante o pagamento de uma indenização ${ }^{51}$. Isto em vista de a resolução ser concebida como sanção extraordinária ou subsidiária, o que explica que o juiz procure sauver le contrat sempre que possível ${ }^{52}$.

No Direito alemão, a partir da cláusula geral $^{53}$ da boa fé, inserta no $\S 242$ do BGB, e, especificamente, do $\S 320$, II, também do $\mathrm{BGB}^{54}$, não se permite ao credor rechaçar uma prestação que lhe seja oferecida, não em sua totalidade, mas na qual falta apenas uma pequena parte em relação ao todo, sem que haja interesse objetivamente fundado que se oponha à aceitação da parte ofereci$\mathrm{da}^{55}$.

Também na Espanha há uma marcada tendência para a manutenção do vínculo contratual, pois exige-se, para o êxito da ação resolutiva, um incumprimento substancial ${ }^{6}$.

$\mathrm{Na}$ Argentina, em vista da boa fé objetiva (artigo 1.198 do Código Civil), também nem todo descumprimento origina a resolução do contrato, apenas aquele que o impede de lograr o fim tutelado pelo ordenamento jurídico e proposto pelos interessados ao utilizá-lo ${ }^{57}$.
No plano do Direito Internacional enconra-se referência, indireta, é verdade, à doutrina do adimplemento substancial na Convenção das Nações Unidas sobre os Contratos de Compra e Venda Internacional de Mercadorias - Viena, 1.980.58. Em seu artigo 25, a Convenşão de Viena dispõe: "uma violação do contrato cometida por uma das partes é fundamental quando causa à outra parte um prejuízo tal que a prive substancialmente daquilo que lhe era legítimo esperar do contrato, salvo se a parte faltosa não previu esse resultado e se uma pessoa razoável, com idêntica qualificação e colocada na mesma situação, não o teria igualmente previsto" 159

Ao abordar a fundamental breach, a Convenção de Viena não distingue se a violação foi de cláusula fundamental ou acessória; condition ou warranty, obrigação principal ou secundária, decorrente do contrato, da própria Convenção ou do princípio da boa fé. $O$ que interessa, para que se configure uma fundamental breach, é que seja causado um prejuízo substancial à contraparte (ainda: imprevisível para uma pessoa razoável), não importando se a infração foi de dever acessório se o prejuízo decorrente for de tal monta ${ }^{60}$.

O que importa, realmente, em se tratando de adimplemento substancial ou inadimplemento fundamental, não é a natureza do dever violado, mas a gravidade objetiva do prejuízo causado ao credor pelo incumprimento. Se este prejuízo é grave o bastante para furtar seu interesse pela prestação, a hipótese será de inadimplemento fundamental, qualquer que tenha sido o dever não cumprido, com o que, a resolução é legítima face ao desequilíbrio que o incum primento trouxe à economia do contrato. Entretanto, se da violação, mesmo que do dever principal, não decorreu prejuízo capaz de comprometer o interesse do credor pela prestação, o pedido de resolução é abusivo, pois se ainda há tal interesse, mantémse o sinalagma: há então um adimplemento substancial. Por isso pode-se dizer que há uma relação de inversão entre tais noções, inadimplemento fundamental $e$ adimple- 

prevista uma, a outra é também aplicável, na medida das circunstâncias concretas.

\section{B. O adimplemento substancial no}

\section{direito brasileiro}

Em nosso sistema jurídico é possível chegar-se à aplicação da doutrina do adimplemento substancial através da conjugação en tre alguns artigos do Código Civil e o princípio da boa fé objetiva. Na verdade, muitas vezes é por ter em mente este princípio que o julgador sai em busca de dispositivos legais que lhe permitam fazer a aplicação, em seu sistema jurídico, de elemento externos a ele. Assim, dá-se que muitos sistemas jurídicos recebem elementos de outros, como ocorre com o adimplemento substancial, com a fundamentação de que estão a aplicar o princípio da boa fé objeti$\mathrm{va}^{61}$. Será necessário, então, verificar, no sistema legal brasileiro, quais os dispositivos que posssibilitam a sua recepção (B. 1.), examinando-se, após, a sua correlação com o aludido princípio (B. 2.).

\section{B.1. A base legal para sua aplicação}

O parágrafo único do artigo 1.092 do Código Civil prevê que, nos contratos bilaterais, "a parte lesada pelo inadimplemento pode requerer a rescisão ${ }^{62}$ do contrato com perdas e danos", não indicando, contudo, os elementos necessários à qualificação deste inadimplemento. É necessário, portanto, buscá-los em outros dispositivos, para que então se determine como é o inadimplemento que justifica a resolução do contrato.

$\mathrm{O}$ artigo 955, também do Código Civil, conceitua mora: "considera-se em mora o devedor que não efetuar o pagamento, e o credor que o não quiser receber no tempo, lugar e forma convencionados", englobando, portanto, as hipóteses de adimplemento imperfeito, inclusive por defeito qualitativo, como a violação quanto à forma e ao modo da prestação. O parágrafo único do artigo 956 indica outro elemento - a inutilidade de prestą̧ão para que o credor possa enjeitá-la, ou seja, resolver o contrato: "se a 68 prestação, por causa da mora, se tornar inútil ao credor, este poderá enjeitá-la e exigir a satisfação das perdas e danos".

Assim, o parágrafo único do artigo 1.092 apenas é aplicável no caso de a mora, o inadimplemento, tornar a prestaf̧ão inútil ao credor. Se, apesar da imperfeição, ainda lhe for útil, aplica-se o artigo 1.056: "não cumprida a obrigação ou deixando de cumprila, pelo modo e no tempo devidos, responde o devedor por perdas e danos".

Vê-se aqui, mais uma vez, que é o interesse do credor pela prestação - a sua utilidade para ele - o critério de aferição da gravidade do incumprimento. Exige-se um inadimplemento que comprometa a substância do contrato para outorgar ao credor o direito de resolução. Se ainda lhe for útil a prestação, mesmo que inexata, o exercício de tal direito é abusivo, contrário aos ditames da boa fé objetiva.

Este raciocínio adapta-se também ao nosso Código Comercial. Seu artigo 202, ao tratar da compra e venda mercantil, como - 1.092 do Código Civil, prevê a possibilidade de resolução do contrato quando o devedor deixa de entregar a coisa vendida no tempo aprazado, salvo os casos fortuitos ou de força maior. Utilizados, subsidiariamente, os critérios apontados no Código Civil, aplicável o artigo 197, semelhante ao 1.056 daquele Código, pois dispõe que "logo que a venda é perfeita (artigo 191), o vendedor fica obrigado a entregar ao comprador a coisa vendida no prazo, e pelo modo estipulado no contrato; pena de responder pelas perdas e danos que da sua falta resultarem". Então, nos casos em que a mora fosse insignificante, não prejudicial ao interesse do comprador, no lugar do artigo 202, poder-se-ia aplicar o 197 , mantendo-se o contrato.

Jâ no âmbito do Código de Defesa do Consumidor, aparentemente, é um pouco mais difícil a aplicação da doutrina. Todas as disposições acerca de imperfeições do produto ou serviço fornecido, objeto da prestação contratada, sem cogitar de sua gravidade, consagram sempre o direito do consumidor à opção entre exigir sua substi- tuição por outro (ou a reexecução do serviç), o abatimento no preço e a restituição da quantia paga (a resolução do contrato) ${ }^{63}$. Se nos atermos à letra da lei e ao espírito do Código - que é a proteção do consumidor sempre lhe será legítimo resolver o negócio. A doutrina do adimplemento substancial, nestas hipóteses, viria em benefício do fornecedor, de encontro, portanto, ao espírito do Código, que surgiu justamente para tutelar o consumidor, considerado naturalmente a parte mais vulnerável da relação.

Tutelando-o, de modo a compensar sua natural vulnerabilidade, alçou-o, entretanto, a uma posição de igualdade jurídica em relação ao fornecedor. Ademais, por tratarse do princípio da boa fé objetiva, não se deve adotar posição sectária e excluir ex radice do CDC, pelas razões acima, a aplicação da doutrina do adimplemento substancial.

$O$ próprio CDC consagra o princípio da boa fé objetiva e, em seu artigo $4^{\circ}$, que lança as luzes para a leitura de todo o Código, indica, no inciso III, que tal princípio atua face às duas partes da relaşão de consumo - o que, aliás, é da própria essência da boa fé objetiva $^{64}$.

A melhor solução, desta forma, parece ser deixar ao julgador a possibilidade de, diante do caso concreto, avaliar a gravidade de um tal inadimplemento, com base no princípio da boa fé objetiva e no conjunto de princípios consignados no artigo $4^{\circ}$ do CDC e, se entendesse abusivo o exercício do direito de resolução, restringir a escolha do consumidor à substituição do produto (ou reexecução do serviço) e ao abatimento do preço.

B.2. A atuação do princípio da boa fé objetiva

Salvo o artigo 131, I, do Código Comercial, que é, na verdade, uma cláusula geral da boa fé - mas cuja expressão é mínima, se não mesmo inexistente como tal em nossa tradição doutrinária e jurisprudencial - não ocorreu a recepção legislativa do princípio da boa fé objetiva em nosso ordenamento positivo até o advento do Código de Defesa do Consumidor ${ }^{65}$
Entretanto, isto não impediria que se o plicasse, de vez que sua vigência independe de positivação, porquanto sua aplicação constitui "o resultado das necessidades éticas essenciais" (cujo afastamento é vedado a qualquer sistema jurídico), embora tal se tornasse difícil justamente em vista de inexistir uma norma de referência em que pudessem os juízes fundar suas decisões ${ }^{66}$.

Baseado em tal princípio, que inform todo o ordenamento jurídico, o juiz elabora a norma aplicável ao caso concreto e as conseqüências jurídicas que daí advirão, num processo de concreção ${ }^{67}$.

Deste modo, porque a boa fé objetiva funciona como "janela" do sistema jurídico, permitindo o conhecimento de elementos externos ainda não positivados na lei (ou já positivados na jurisprudência), é possível que a decisão se dê para além do que estava programado ou mesmo em contrário a algum preceito expresso ${ }^{68}$, que assim é reelaborado ou desconsiderado, face à atuação prevalente do princípio ${ }^{69}$.

Esta é a grande transformação que pode causar sua incidência em sistemas jurídicos onde persistem ainda certas conseqüências do princípio da autonomia da vontade e do dogma da absolutização dos direitos ${ }^{70}$, na medida em que mitiga a atuação destes, pela eticização que introduz no Direito.

A boa fé objetiva engendra uma norma jurídica completa, que se eleva à categoria de um princípio geral de direito: todas as pessoas, todos os membros de uma comunidade jurídica devem comportar-se segundo boa fé objetiva em suas relações recíprocas, o que se projeta nas duas direções em que se diversificam todas as relações jurídicas - direitos e deveres. Assim, os direitos devem ser exercidos de acordo com a boa $f^{\prime}$, e as obrigações, cumpridas conforme a boa fé objetiva ${ }^{71}$.

A preocupação ética com o enquadramento social do indivíduo e sua conseqüente responsabilidade social, atua, desde a primeira grande guerra, na ampliação do princípio da boa fé, na integração da teoria da vontade através do princípio da proteção da confiança, no esforço direcionado à jus- 
tiça contratual material, na limitação do uso da propriedade através da ênfase em sua vinculação social e, entre outros exemplos ainda, na funcionalização dos direitos de crédito, que é o que, especificamente, aqui nos interessa ${ }^{72}$.

No que tange à doutrina do adimplemento substancial, relativiza a aplicação do instituto da resolução, típico dos ordenamentos "inspirados nos princípios da liberdade e autonomia privadas"1/3, por uma questão de justiça substancial e de eqüidade.

O princípio da boa fé objetiva aí atua de forma a proteger o devedor frente a um credor malicioso, inflexível (boa fé eximente ou absolutória ${ }^{74}$ ), como causa de limitação do exercício de um poder jurídico, no caso, do direito formativo de resolução, do qual é titular o credor de obrigação não cumprida ${ }^{75}$.

Se a obrigação foi substancialmente adimplida, o pedidó de resolução não trará nenhum benefício legítimo ao credor, apenas prejuízos para o devedor que, tendo praticamente satisfeito a totalidade da obrigação, verá tudo retornar ao status quo ante.

Nesta hipótese, portanto, o exercício do direito de resolução é abusivo. Em si mesmo, o direito é válido. Torna-se um abuso de direito quando exercido de forma que ofende o sentimento de justiça dominante na comunidade social ${ }^{76}$.

Tal ofensa ocorre quanto este exercício excede manifestamente os limites impostos pela boa fé objetiva, pelos bons costumes ou fím social ou econômico deste direito ${ }^{77}$. Trata-se do problema da funcionalização dos direitos em contraposição ao já superado dogma do absolutismo dos direitos, o qual permite seu exercício sem cogitar de sua vinculação social. Hoje ${ }^{+} a$ ênfase encontra-se nesta nota.

O direito de resolução é medida protetiva em relação ao credor. Visa a evitar a possibilidade de que ele, contratante não inadimplente, venha a sofrer, além da injúria do incumprimento, ainda a iniqüidade de ver a sua prestação, porventura já executada, restar no patrimônio do inadimplente. Seu objetivo é, portanto, resguardar a reciprocidade, no sentido de evitar uma in70 justa distribuição das utilidades de fato realizadas pelas partes através do contrato pelo perigo de um enriquecimento injusto da parte inadimplente em detrimento da outra $^{78}$

Ocorre que o mesmo perigo há em se permitir uma resolução de contrato substancialmentemente cumprido. Em se tendo beneficiado, o credor que recebeu a prestação insignificantemente inexata estaria apenas prejudicando aquele que assim a ofereceu, se propugnasse pela resolução.

A resolução determina a restituição, por cada das partes, daquilo que havia recebido por força do negócio jurídico ora resolvi$\mathrm{do}^{79}$. Muitas vezes, entretanto, como demonstra a experiência jurídica anglo-americana, a restituição da prestação incompleta que, ainda assim, satisfaz ao credor, de nenhuma utilidade é para aquele que a prestou, fazendo-o, então, perder o material e o trabalho nela empregados ${ }^{80}$. Em outros casos, a restituição é de tal forma desvalorizada em relação ao devedor que, se comparada ao que devolve para o credor, representa enriquecimento sem causa deste ${ }^{81}$

Aí está o excesso, o abuso, mesmo o contra-senso na resolução, em caso de ter havido adimplemento substancial. Abusiva também, a exceção de contrato não cumprido quando o incumprimento é insignificante em relação à totalidade do devido. E, por isso, são vedadas. Mas, para que o credor não reste prejudicado, pois, a rigor, tem direito a uma prestação exata, concede-selhe o direito de exigir o cumprimento da parte omitida e/ou perdas e danos.

\section{B.3. Soluções jurisprudenciais}

O Tribunal de Justiça do Rio Grande do Sul, por sua 5a Câmara Cível, vem prolatando decisões que acolhem a doutrina do adimplemento substancial.

$\mathrm{Na}$ Apelação Cível no 588016147, em que foi Relator o Desembargador Ruy Rosado de Aguiar Jr., por unanimidade, em 03 de abril de $1.988^{82}$, estabeleceu-se que em contrato de compra e venda de imóvel com defeitos na construção, não sendo estes su- ficientes para caracterizar o inadimplemento do vendedor/construtor, o contrato fora mal cumprido, incidindo na espécie, entretanto, o artigo 1.056, e não o 1.092, ambos do Código Civil. Isto porque o apartamento, objeto do contrato, não apresentava vícios quanto à sua estabilidade e solidez, apenas condições deficientes para a habitação, que poderiam ser sanadas. Assim, foi mantido o contrato e condenado o vendedor/construtor ao pagamento de indenização suficiente para cobrir integralmente as despesas para a reforma do imóvel, de forma a assegurar sua perfeita habitabilidade, com a sanação dos vícios ali existentes.

$\mathrm{Na}$ Apelação Cível no 589016534, a mesma Câmara, com o mesmo Relator, também por unanimidade, em 02 de maio de $1.989^{83}$ julgou improcedente Ação Ordinária de Resolução de Contrato proposta pela construtora/vendedora. Neste caso, também de contrato de compra e venda de imóvel, havia mora da construtora em entregá-lo e pagamento parcial do preço pelo comprador. Decidido foi que não se poderia resolver o contrato em benefício exclusivo da construtora (que, por sua atitude, fez com que o comprador adimplisse apenas parcialmente, embora desejasse fazê-lo de todo), pois esta retomaria a posse e propriedade do imóvel já valorizado, enquanto seu co-contratante receberia de volta valores desatualizados - prejuízo injusto uma vez considerado que havia cumprido substancialmente o que lhe competia na execução do contrato: quase a totalidade do preço ajustado.

Também na Apelação Cível no 588012666, a mesma Câmara, com o mesmo Relator novamente à unanimidade, em 12 de abril de 1.988, julgou improcedente Ação de Resolução porque o devedor havia cumprido substancialmente a sua obrigação, não podendo. ser o atraso na última prestação causa justificadora da resolução do negócio ${ }^{84}$.

Conclusão

Afirmou-se inicialmente que o exame da doutrina do adimplemento substancial sus- cita os grandes temas do moderno Direito as Obrigações.

Por isto mesmo a sua aplicação supõe a prévia compreensão da relação obrigacional como uma "ordem de cooperação entre as partes" e não mais como uma rígida polarização entre credor e devedor, tidos como antagonistas no jogo social. Pressupõe, bem assim, a clara compreensão dos modos do atuar do princípio da boa fé objetiva, prin. cipalmente em sua feição limitadora do exercício de poderes jurídicos e criadora de deveres de conduta, anexos aos deveres principais que decorrem da relação obrigacional concretamente considerada. Tais fatores conduzirão, por seu turno, a que o juiz, não mais um mero "aplicador" da lei estratificada, avalie a possível insignificância do descumprimento de certa obrigação, em face da função econômico-social perseguida pelo contrato como sua causa, considerando, ao par dos interesses do credor, também os interesses do devedor, de forma a protegê-lo contra eventuais abusos do credor.

Mas não apenas no campo doutrinário justifica-se a importância do seu estudo.

Quando do surgimento das grandes codificações, no século XIX, confundiu-se Direito e lei como se ambos fossem sinônimos ou como se aquele estivesse totalmente compreendido nesta. Hoje, superado o dogma da "completude da lei escrita", sabe-se que o Direito nem sempre se identifica exclusivamente com a lei. Por outro lado, se a lei pode ter um caráter nacional, o Direito, a Ciência do Direito, por sua natureza de ciência, tem caráter transnacional, o que permite aos juristas aproveitar as experiências jurídicas estrangeiras como elementos úteis "na realização de uma justiça mais adequada aos concretos problemas nacionais. $O$ "adimplemento substancial" é uma destas experiências e, como visto, pode ser, com os convenientes ajustes, perfeitamente inserida em nosso sistema.

\section{Notas}

${ }^{1}$ No Direito Romano e na Pandectística, a obrigação é vista como um vínculo estático: de um lado, o direito
subjetivo de receber o crédito, de outro, o dever jurí- 
dico de pagar o débito, ou seja, credor e devedo situados em dois pólos apartados, em posições antago nicas, sendo, o primeiro, titular dos direitos e, o segu do, dos deveres e nada mais

Modernamente, não mais vige esta concepf̧ão. A rel ção obrigacional passa a ser compreendida como u processo de cooperação, o vínculo obrigacional pas a ser visto de forma dinâmica, dele decorrendo dever para ambos os pólos da relação jurídica. Isto, em vi tude do entendimento de que esta relação é polarizad por uma finalidade tutelada pelo direito: a cooperação social mediante o intercâmbio de bens e serviços. Para que tal finalidade seja alcançada, é necessário que a
obrigação seja cumprida, resultando daí que a relação obrigação seja cumprida, resultando daí que a relação obrigacional deixa de ser apenas a soma de crédito e débito, estaticamente considerados. Na medida em que é compreendida como uma ordem de cooperaçào, ao dever principal agregam-se deveres anexos, que perm tem atingir o pleno adimplemento, i. é, a satisfaçào total do credor em seu interesse na prestação. E, des forma, os binômios credor/devedor, direito subjet vo/dever jurídico, embora permaneçam o cerne da re laçào obrigacional, já não esgotam o seu conteúdo, pois, na verdade, trata-se de uma relação obrigaciona complexa, integrada por um conjunto de direito deveres recíprocos que, portanto, atingem ambas as partes.

Sobre o tema, v. Clóvis do Couto e Silva, A Obrigação como Processo cit, Karl Larenz, Mário Júlio de Almeinuel da Rar cits.

2 V. adiante, parte II, B.2., A atuação do princípio d boa fé objetiva.

${ }^{3}$ A causa do negócio jurídico deve ser compreendida em sentido teleologico e deontologico, atinente à exigência de sociabilidade que preside à função ordenadora do direito. Tal como os direitos subjetivos, também os poderes de autonomia, efetivamente, não devem ser exercidos em oposição com a função social a que são destinados: o instrumento da autonomia privada, colocado à disposição dos individuos, não deve ser desviado do seu destino" (Emilio Betti, Teoria Geral do Negócio Jurídico cit., p. 334). Considerada sob o a pecto social, "a causa do negócio é, propriamente, função econômico-social que caracteriza o tipo desse negócio como fato de autonomia privada (típica, nes sentido), e lhe determina o conteúdo mínimo necess rio" (idem, p. 352). Limita, assim, a autonomia priva$\mathrm{da}$, pois a tutela jurídica desta "toma em conta, não capricho individual, mas apenas a função socialmente relevante do negócio-tipo, considerada em si e por si" (idem, p. 357). O mesmo vale para o direito de resoluçào.

Em geral, o fundamento da resolução é coligado aos conceitos de contrato comutativo, se sinalagma e é importante $o$ inadimplemento cuja gravida objetiva, sobre a funcionalidade do contrato, gravidade incide the a causa ou turbar o equilibrio funcional entre as 72 atribuições recíprocas que as partes pretenderam atingir com a regulação contratual. Assim, o descumprmento por um dos contratantes repercute imediat mente sobre o sinalagma contratual, comprometendo função econômico-social do contrato, i. é, a sua caus (M. Rosa Spallarossa, art. cit., pp. 53 e ss).

${ }^{4}$ Neste sentido, Clóvis do Couto e Silva, A Obrigação como Processo cit.

5 É imprescindivel a discriminação entre a boa fé subjetiva e a boa fé objetiva. Na primeira, "a boa f aparece como atitude da consciência, que é objeto de ma interpretação psicológica; atitude consistente na ignorância de que se está a prejudicar um interesse alheio tutelado pelo direito (...) Trata-se de um estado psicológico que se manifesta na ignorância da circunstância decisiva, que imprimiria caráter de ilicitude conduta, se não houvesse sido ignorada; ignorância em consequência, que atribui a qualificaçāo de correta à conduta de quem dela padece" (Emilio Betti, Teoria General de los Obligaciones, Tomo I, pp 74 e ss). Quanto ao princípio da boa fé objetiva, no Brasil, há relativamente poucos estudos a respeito (v. por exemplo, Antonio Junqueira de Azevedo, A Boa Fé na For mação dos Contratos, in Revista de Direito do Consumidor, vol. 3, set-dez 1.992), em que pese a grande relevância que possui na atualidade, especialmente no âmbito do Direito das Obrigaçōes, onde se manifesta como mína objetiva que determina aumento de deveres, além daqueles que a convencão aumento de constitui (deveres a cicipes do vinculo ex parcriar deveres para rado titular de direitos" (Clóvis do Couto e Silva, A Obrigcio como Processo cit, p. 29). "Tal manda, A Obraça con o de condo en inculo obrigacional e estabelece, entre eles, um elo de cooperação, em face do fim objetivo a que visam (idem, p. 30). Exige-se, nas relações obrigacionais, "uma atitude positiva de cooperação, uma atitude em favor do interesse alheio, e a bona fides consiste em um critério de conduta inspirado e informado pelo interesse da outra parte; conduta dirigida ao cumprimento positivo da expectativa de cooperação da contraparte (Emilio Betti, ob. cit. p. 86). É "um standard ou modelo ideal de conduta social. Aquela conduta social que se considera como paradigmática" (Luis Diez-Picazo, in Prólogo à ob. cit. de Franz Wieacker, p. 19).

Promanam de sua concreção judicial (v. nota n. 20, infra), além de deveres de conduta anexos, exigiveis em cada caso de acordo com a natureza da relação jurídica e a finalidade perseguida pelas partes através dela, limitações ao exercício dos direitos subjetivos ou de quaisquer outros poderes juridicos (Luis Diez-Picazo, Gem ibidem), como se dá na hipótese do adimplemento substancial.

Destaca ainda Clóvis do Couto e Silva (O Princípio da Boa Fé ... cit., p. 47), que "a aplicação do princípio da boa fé (objetiva) com a criação ou compreensão científica dos deveres secundários ou anexos, aproxima o conceito de relação obrigacional vigorante no Direito germânico com o da common law".

6 v. Clóvis do Couto e Silva, A Obrigação como Processo cit.

7 in O Princípio da Boa Fé cit., p. 56.

8 v. adiante, Parte II, A

9 v. Bernard Gilson, ob. cit., pp. 86 e ss.

10 A noção de consideration, tal como a de causa no sistema romano-germânico, surgiu com a finalidade de limitar o principio da autonomia da vontade.

Em seu sentido clássico, o que aqui nos interessa, de vez que vigente na época que enfocamos, corresponde à contraprestação em vista da qual alguém se obriga a prestar algo (Bernard Gilson, ob. cit., p. 27). Desta forma, a idéia de consideration exprime o caráter oneroso do acordo concluído (idem, p. 95). Este faz nascer obrigaçōes recíprocas. A operação de troca - dita barobrigaçós reciprocas. A op

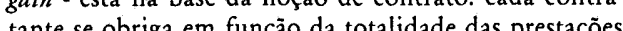
que a outra parte cumpriń (idem, p. 156), mas somes que a outra parte cumprira (idem, p. 156), mas somen-

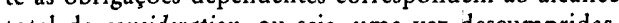
abalam profundamente o equilibrio contratual.

"A existência do contrato depende da reciprocidade pois todo contrato deve ser oneroso: a condition $\dot{c}$ toda pois todo contrato derer ser cláusula cuja inexecuçà afe a a talidade da conside

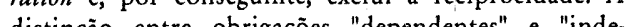

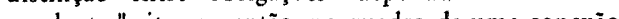
pend des" situase, entazo, no ques de uma conexan tes, que explica a consideration (idem, p. 102).

tes, que explica a consideration (idem, p. 102).
Sobre o tema, v. também René David, Les Contrats en

Droit Anglais cit.; Mário Diaz Cruz, Causa y ConsideDroit Anglais cit.; Mario Diaz Cruz, Causa y Conside-
ration en los Contratos - Inútiles Ejercicios de Dialéctica, in Comparative Juridicial Review, vol. 23, 1.986; Basil Markesinis, La Notion de Consideration dans la Common Law, in Revue Internationale de Droit Comparé, out-dez 1.983, n. 4, que refere Atiyah, The Rise paré, out-dez 1.983, n. 4, que refere
and Fall of the Freedom of Contract.

${ }^{11}$ A referência, aqui, é à ratio decidendi do julgamento, i. é, aquilo que constitui o suporte necessário da decisão, segundo René 'David (Os Grandes Sistemas... cit., p. 343), ou, conforme Rupert Cross (Precedent in English Law, Clarendon Press, Oxford, 1.977, p. 76), "uma regra de direito expressa ou implicitamente tratada pelo juiz como um passo necessário para alcançar a sua decisão, considerando-se a linha de raciocínio por ele adotada". Esta regra se incorpora no Direito inglês e deve, a este título, ser seguida no fututo, constituindo-se no precedente.

12 apud Bernard Gilson, ob. cit., p. 87, tradução nossa. 13 Tecnicamente, é imprópria a expressão "resolução do contrato", uma vez que a resolução dissolve a relação contratual e não o contrato, que é a declaração que a gera, a qual não e passivel, ela propria, de resolução. V. Enrico Dell'Aquila, art. cit. p. 857

14 v. adiante, Parte II, A.

15 Cheshire e Fifoots, Law of Contracts cit., p. 487.
16 in Bernard Gilson, ob. cit., p. 33. 17 v. Bernard Gilson, ob. cit., p. 223.

in Law of Contracts cit., p. 480

19 Bernard Gilson (ob. cit., p. 223) diz, entretanto, que os tribunais ingleses muiro raramente a utilizam, preferindo declarar acessorias as insuficiências, com base nas noçoes de "obrigaçăo independente" e warrany. De odo modo, o que prevalece é a solução mais próxim justiça material.

${ }^{20}$ Os conceitos jurídicos indeterminados e os princípios gerais de direito são pautas de valoração "carecidas de preenchimento valorativo". Com esta expressão, quer-se dizer que o volume normativo destes conceitos tem de ser preenchido caso a caso, através de atos de valoração (Karl Engish, ob. cit.). Isto significa que, ao operá-los, a tarefa do julgador não se pode restringir uma rígida subsunção, de vez que tais pautas exigem mais do que a aplicação mecânica da norma. Exige uma mudança na própria concepção de sistema jurídi$c o$, o qual deve ser concebido de forma relativamente aberta, para permitir a inserção de valores extra-jurídico Cabe ao juiz, desta forma, uma margem residual de livre apreciação do caso singular. Entretanto, a concretização de tais pautas, como os "bons costumes", a "boa é objetiva", a "diligência devida" no tráfego, etc., não constitui um processo irracional ou arbitrário. $\mathrm{Na}$ verdade, a tarefa do julgador é precisamente a "materialização" das valorações. Incumbe-lhe, por isso, um valorar ligado a princípios jurídicos com a ajuda de um pensamento "orientado a valores", i. é, em conform dade às exigências e pautas de valoração do ordenamento jurídico, encontráveis, especialmente, na Constituição e nos princípios por ela consagrados. Deste modo, a direção que o julgador deve seguir, pelo menos, é traçada.

Por outro lado, toda a concretização alcançada ao julgar um caso singular desenvolve, ao mesmo tempo própria pauta. "Aplicação do Direito e desenvolvimento do Direito caminham aqui de par um com outro, são um e o mesmo processo" (Karl Larenz Metodologia da Ciência do Direito, Fundação Calouste Gulbenkcan-Lisboa, 1.989)

${ }^{21}$ Bernard Gilson, ob. cit., Cheshire e Fifoots, obs. cits., Corpus Juris Secundum, vol. 17A, Ruling Case aw, vol. 6 e American Law Reports, vol. 19

22 João Baptistà Machado (art. cit., p. 352) anota que gravidade da inexecução, por si só e diretamente, não influi sobre o direito a indenizaçăo: qualquer que seja a extensão ou importância da inexecução, desde que esta seja imputável ao devedor, impõe-se a reparação dos danos derivados do incumprimento.

${ }^{23}$ Bernard Gilson (ob. cit., p. 144), comentando o Restatement of the Law of Contract (EUA), diz que a erave antes, em funcio do coniunto de obrigacoes de cada uma das partes. Assim a resolucio se justifica mais pela in partes. Assim, a resoluça pela inexecuçâo fatal do
cláusula reputada essencial. 
${ }^{24}$ Ruling Case Law, vol. cit., p. 971.

25 idem, p. 969.

26 conforme Luis Diez-Picazo, citado por José Carlos Brandão Proença, art. cit., p. 377, n. 409. V. também João Baptista Machado, art. cit., pp. 391 e 392.

27 "O dono de uma construção tem o direito de escolher o que deseja construido para si, e não deve ser compelido a receber algo diverso" (Ruling Case Law, vol. cit., p. 969).

${ }^{28}$ Caso Meincke v. Falk, EUA, 1.884, in American Law Reports, vol. cit., p. 820 e Ruling Case Law, vol. cit., p. 966

${ }^{29}$ Franz Wieacker, ob. cit., p. 58 .

30 idem, p. 59.

${ }^{31}$ Assim decidido no caso Newcomb v. Schaeffer (EUA), in Corpus Juris Secundum, vol. cit., p. 816, n. 53.5, tradução nossa.

32 v. caso Hoenig v. Isaacs, julgado na Inglaterra em 1.952 , in Cheshire e Fifoots, Cases on the Law of Contracts cit., pp. 427 a 429.

${ }^{33}$ Luis Diez-Picazo, conforme João de Matos Antunes Varela, Das Obrigações em Geral, vol, II, Almedina, Coimbra, 1.980, p. 123, n. 1.

34 "Le retard dans l'exécution n'est pas essenciel, sauf si la nature de l'affaire confere une importance spéciale au respect de la date prescrite pour exécuter" (Bernard Gilson, em comentário ao Restatement of the Law of Contract (EUA), ob. cit., p. 143).

35 Já a perda do interesse puramente subjetiva, fruto de capricho, não justifica a recusa da prestação, por não ser digno de tutela jurídica. V. Antunes Varela, ob. não ser digno
cit., p: 120 .

${ }^{36}$ Luis Diez-Picazo, in Prólogo da ob. cit. de Franz Wieacker, p. 12.

${ }^{37} \mathrm{~A}$ doutrina italiana costuma distinguir entre o dever de boa fé e o dever de diligência, considerando o primeiro como a modalidade concreta de atuação da prestação devida e o segundo como a medida de esforço exigivel (Umberto Breccia, apud Menezes Cordeiro, ob. cit., n. 288, p. 611). Tal se deve à peculiaridade de o Código Civil Italiano tratá-los em dispositivos distintos. A preocupação demasiada com a distinção tem conduzido a um menor aprofundamento do verdadeiro sentido e conteúdo do princípio da boa fé objetiva, devendo, portanto, ser integrada (Menezes Cordeiro, idem, ibidem). V. sobre o tema, C. Massimo Bianca e Giovanni Maria Uda, arts. cits.

${ }^{38}$ Massimo Bianca, art. cit., p. 210

${ }^{39}$ Percebe-se aqui, claramente, a dimensão de peso ou importância, própria dos princípios e que falta às normas. Quando os principios se interferem, no caso, aquele que determina a apreciação objetiva do adimplemento e o que exige diligência por parte do devedor, o julgador deve considerar o peso relativo de cada um, o que varia segundo as circunstâncias de cada caso concreto. Um princípio não estabelece as condiçōes que se fazem necessárias para sua aplicação. Apenas enuncia uma razão que milita em favor de uma orientação geral, mas que não necessita de uma decisão particular. Se um contratante não agiu diligentemente esta é uma razão que se terá em conta para decidir se seu adimplemento foi mesmo substancial. Pode ha ver outros princípios que apontem em direça contraria e em tal caso é possível que aquele princípio na prevalesa mas isto não significa a sua exclusão no sistema juridico (como ocorreria em se tratando de uma norma) porque num caso seguinte, quando de considerações não existam ou não tenham o mesmo peso, aquele princípio pode ser decisivo. Sobre o tema peso, aquele principio pode ser decisivo. Sobre o tema
v. Ronald Dworkin, Los Derechos en Serio, Ariel, Barcelona, pp. 72 e ss.

${ }^{40}$ Caso Gillespie Tool Co. v. Wilson, in American Law Reports, vol. cit. pp. 813 e 814 . V. também Corpu Juris Secundum, vol. cit. p. 815, n. 49, traduçáo noss ${ }^{41}$ Caso Ehrlich v. U.S. Fidelity o Guaranty Co., in Corpus Juris Secundum, vol. cit. p. 815, tradução nossa. 42 Corpus Juris Secundum, vol. cit., pp. 822 e 823.

$43 \mathrm{O}$ direito formativo é uma espécie de direito subjeivo, ainda não formado (dai porque formativo), ma que se está formando, possuidor de um titular que, ao exercê-lo, constitui, modifica ou extingue uma relação uridica. A ele não corresponde um dever, nem mesmo sendo admissivel a existência de um dever de tolerar seu exercicio, pois não há dever de tolerância com relação ao que de modo algum se pode evitar. Corres ponde-lhe, assim, um estado de sujeição pura e simples os efeitos que dele irradiam, por parte do outro termo a relação jurídica. Uma vez exercitados, consomem-se, dando origem a um direito subjetivo formado. Sobre o tema, v. Almiro Régis do Couto e Silva, Atos Jurídicos de Direito Administrativo Praticados por Particulares e Direitos Formativos cit.

$44 \mathrm{O}$ fundamento da ação de resolução por incumprimento do devedor reside no "princípio de justiça comutativa, do qual emerge a regra de equivalência entre as prestaçōes correspectivas e a defesa do credor não inadimplente" (Ruy Rosado de Aguiar Jr., ob. cit., 269, conclusão n. 9).

${ }^{45}$ Ruling Case Law, vol. cit., § 342, tradução nossa.

${ }^{46}$ Mondel v. Steel (1.841), decisão considerada um avanço na jurisprudência inglesa. Mondel encomendou um navio a Steel. Como o navio entregue não conseguiu suportar o mau tempo durante sua primeira viagem, Mondel propôs ação de indenização, julgada procedente, em vista das altas despesas que fora obrigado efetuar com sua reparação. In Bernard Gilson, ob. cit., pp. 225 e 226.

47 Sobre o tema, v. Corpus Juris Secumdum, vol. 25, $\S \S 96$ e 97.

48 Conforme Carlo Rossello, citado por Ruy Rosado de Aguiar Jr., ob. cit., p. 136, n. 252.

49 "Il contratto non si pùo risolvere se l'inadempimento di una delle parti ha scarsa importanza, avuto riguardo allinteresse dell'altra".
50 v. M. Rosa Spallarossa, art. cit.

51 Assim noticiado por Adolfo Klitsche de la Grange, art. cit., pp. 41 e 42.

52 Segundo René Cassin, apud José Carlos Brandão Proença, art. cit., p. 363 , n. 366

53 Do ponto de vista metodológico, as cláusulas gerais nào possuem qualquer estrutura própria, pois năo exigem processos de pensamento diferentes daqueles que são requeridos pelos conceitos jurídicos indeterminados, por exemplo. "O verdadeiro significado das cláusulas gerais reside no domínio da técnica legislativa. Graças à sua generalidade, elas tornam possivel sujeitar um mais vasto grupo de situações, de modo ilacunar e com possibilidade de ajustamento, a uma conseqüência juridica O casuísmo está sempre exposto ao risco de junica O cuśri jurílica apenas fragmentária e prodomisoriten (Karl Engish, ob. cit. pp. 233 e 234). Por visoriamene (Karl Engish ob. meio da técnica das clausulas gerais, o orgão aplicador do Direto é chamado a descobris o Direito do caso concreto, não simplesmente atraves da interpretação e da subsunçăo, mas tambên ah 248), o "valoraçðes decisões de vontade (idem, p. 248), o que permite a introdução de elementos tradicionalmente tidos como extralegais no sistema juridico, proporcionando-lhe uma relativa abertura (v. Judith MarinseCosta, As Cláusulas Gerais como Fatores de Mobilidade do Sistema Jurídico cit.).

54 Este dispositivo se refere às hipóteses de cumprimento parcial e diz que, em tal caso, não é possível a recus a parcial ediz que esta negativa, de acordo com as à contraprestaçáo se esta negalia, de acordo com as cil insignifincia da parte na en vumprida for contranal insignificancia da parte não cun

55 Karl Larenz, ob. cit., p. 150.

56 Assim noticia José Carlos Brandão Proença, art. cit. p. 363 , n. 366.

57 Aqui Juan Luis Miquel (ob. cit., p. 141) situa o fundamento do instituto da resolução na frustração da causa do contrato (no sentido que lhe dá a doutrina italiana: função econômico-social do contrato. V. nota 3 , supra).

58 v. Ruy Rosado de Aguiar Jr., A Convenção de Vien cit. 'e Vera Maria Jacob de Fradera, O Conceito de Inadimplemento Fundamental ... cit.

59 "A breach of contract committed by one of the parties is fundamental if it results in such detriment to the other party as substancially to deprive him of what he is entilled expect under the contract, unless the party in breach did not foresee and a reasonable person of the same kind in the

circunstances would not bave foreseen such a result". ${ }^{60}$ Neste caso, entretanto, mais convém falar em quebra positiva do contrato. Sobre o tema, v. Vera Man in Revist de Fradera, A Quebra Positiva do Contro de 1.988.

${ }^{6}$ Clóvis do Couto e Silva, O Princípio da Boa Fé cit., p. 48.
62 O emprego do termo "rescisão", neste caso, é impróio devendo ser substituído por "resoluçāo", instituto , qual se trata, efetivamente. V. Pontes de Miranda, ob. e vol. cits., p. 337

${ }^{63}$ Artigos 18, $\S 1^{\circ} \mathrm{e}$ incisos, $19 \mathrm{e}$ incisos e $20 \mathrm{e}$ incisos. 64 A boa fé objetiva é, essencialmente, um critério de reciprocidade que deve ser observado mutuamente nas relaçōes intersubjetivas. Reciprocidade, esta, em que se manifesta a solidariedade que liga os participantes de uma comunidade um ao outro e que explica como o critério de boa fé objetiva deve ter uma orientacão bilateral e, portanto, como pode operar no sentido de ampliar as obrigacões literalmente assumidas mediante contrato ou, eventualmente, de restringir estas obri- conos nos casos e na medida em que contrariam aque gaços nos casos e na medida em que contrariam aque Betti, Teoría General de las Obrigaciones cit., pp. 102 e 103).

65 O Projeto de Código Civil Brasileiro de 1.975, entretanto, já o consagra.

66 v. Clóvis do Couto e Silva, O Princípio da Boa Fé .. cit., pp. 61 e 62 .

67 v. nota $\mathrm{n}^{2} 20$, supra.

68 É o que pode ocorrer, por exemplo, com os artigos $18, \S 1^{2} \mathrm{e}$ incisos, 19 e incisos e 20 e incisos do Código de Defesa do Consumidor, conforme afirmado acima, Parte II, B. 1.

69 Ruy Rosado de Aguiar Jr., ob. cit., p. 243.

70 v. Mário Júlio de Almeida Costa, ob. cit., p. 56.

71 Luis Diez-Picazo, Prólogo cit., p. 12. V. Também nota $\mathrm{n}^{\circ} 64$, supra.

72 v. Ludwig Raizer, art. cit., p. 12.

73 Giaquinto, expressando opinião comum, apud $\mathrm{M}$. Rosa Spallarossa, art. cit., n. 3, p. 455

74 segundo Ramella, citado por Ruy Rosado de Aguiar Jr, ob. cit., p. 250.

75 Em relacão ao devedor, como já visto, age criando dever de diligencia no cumprimento da obrigação.

76 Mário Júlio de Almeida Costa, ob. cit., pp. 58 e 59.

77 De acordo com o artigo 334 do Código Civil de Portugal, "é ilegítimo o exercício de um direito quando o titular exceda manifestamente os limites impostos pela boa fé, pelos bons costumes, ou pelo fim social ou econômico desse direito

78 Enrico Dell'Aquila, art. cit., pp. 858 e 859

79 Pontes de Miranda, ob. e vol. cits., p. 336.

80 v. Corpus Juris Secundum, vol. cit., p. 813

$81 \mathrm{v}$. infra, B. 3.

82 in RJTJRGS, $\mathrm{n}^{\circ} 133$, pp. 343 e ss.

83 in RJTJRGS $\mathrm{n}^{\mathrm{o}} 145$, pp. 219 e. ss.

${ }^{84}$ in Revista AJURIS, vol. 50, pp. 210 e ss. 


\section{Bibliografia}

Aguiar Jr., Ruy Rosado de. Extinfão dos Contratos por Incumprimento do Devedor (Resolução). Aide, Rio de Janeiro, 1.991.

---A A Convensão de Viena e a Resolusão do Contrato por Incumprimento. Datilogr., Porto Alegre, 1.991.

American Law Reports - Annotated, vol. 19. The Lawyers Co-operative Publishing Co., New York, 1.922.

Betti, Emílio. Teoria General de las Obligaciones, tomo I. Ed. Revista de Derecho Privado, Madrid, ${ }^{1} .969$. --. Teoria Geral do Negócio Jurídico, tomo I. Coimbra Ed., Coimbra, 1.969.

Bianca, C. Massimo. La Nozione di Buona Fede quale Regola di Comportamento Contrattuale, in Rivista di Diritto Civile, ano XXIX, no 3, maio-junho de 1.983 Cheshire and Fifoots. Cases on the Law of Contracts. Butterworths, London, 1.977.

---. Law of Contracts. Butterworths, London, 1.981.

Cordeiro, Antônio Manuel da Rocha e Menezes. $D a$ Boa Fé no Direito Civil, vol. I. Almedina, Coimbra 1.984.

Corpus Juris Secundum, vol. 17A. The American Law Book Co., New York, 1.963

Costa, Mário Júlio de Almeida. Direito das Obrigafóes. Almedina, Coimbra, 1.979

Couto e Silva, Almiro Régis do. Atos Jurídicos de Direito Administrativo Praticados por Particulares e Direitos Formativos, in Revista de Direito Administrativo, vol. 95, Rio de Janeiro, janeiro-março de 1.969.

Couto e Silva, Clóvis Veríssimo do. A Obrigąáa como Processo. José Bushatsky Ed., São Paulo, 1.976

---. O Princípio da Boa Fé no Direito Brasileiro e Português, in Estudos de Direito Civil Brasileiro e Português. Ed. RT, São Paulo, 1.980.

David, René. Les Contrats en Droit Anglais. Librairie Générale de Droit et de Jurisprudence, Paris, 1.973 --.. Os Grandes Sistemas do Direito Contemporaneo. Martins Fontes, São Paulo, 1.986

Dell'Aquila, Enrico. La Ratio della Risoluzione del Cantratto per Inadempimento, in Rivista di Diritto Civile, ano XXIX, $\mathrm{n}^{\circ}$ 6, novembro-dezembro de 1.983 .

Dworkin, Ronald. Los Derechos en Serio. Ariel, Barcelona, 1989

Engish, Karl. Introdufão ao Pensamento Jurídico. Fundaçào Calouste-Gulbenkian, Lisboa, 1.988.

Estacaille, Jorge Priore. Resolución de Contratos Civiles por Incumplimiento, tomo II. Amalio Fernandez, Montevideo, 1.974

Fradera, Vera Maria Jacob de. A Quebra Positiva do Contrato, in Revista AJURIS, $\mathrm{n}^{\circ} 44$, Porto Alegre, novembro de 1.988
--. 0 Conceito de Inadimplemento Fundamental do Contrato no Artigo 25 da Lei Internacional sobre Vendas, da Convensão de Viena de 1.980. Datilogr., Porto Alegre, 1.989

Gilson, Bernard. Inexícution et Résolution en Droit An. glais. Librairie Générale de Droit et de Jurisprudence, Paris, 1.969.

Grange, Adolfo Klitsche de la. Risoluzione per Inadempimento e Potestá del Giudice, in Rivista di Diritto Civile, ano $X, \mathrm{n}^{\mathrm{e}} 1$, janeiro-fevereiro de 1.964 .

Larenz, Karl. Derecho de Obligaciones, tomo I. Ed. Revista de Derecho Privado, Madrid, 1.958.

Machado, João Baptista. Pressupostos da Resolução por Incumprimento, in Boletim da Faculdade de Direito da Universidade de Coimbra, Estudos em Homenagem ao Prof. Dr. J. J. Teixeira Ribeiro, 1.979.

Martins-Costa, Judith. As Cláusulas Gerais como Fatores de Mobilidade do Sistema Jurídico, in Revista de Informação Legislativa, ano 28, no 112, Brasilia, outubro. dezembro de 1.991.

--. A Teoria da Causa em Perspectiva Comparativista: a Causa no Sistema Civil Francês e no Sistema Civil Brasileiro, in Revista AJURIS, $\mathrm{n}^{\circ} 45$, Porto Alegre, março de 1.989.

Princípio da Boa Fé, in Revista AJURIS, $\mathrm{n}^{2} 50$, Porto Alegre, novembro de 1.990

Miquel, Juan Luis. Resolución de los Contratos por Incumplimiento. Depalma, Buenos Aires, 1.986.

Mosco, Luigi. La Risoluzione del Contratto per Inadempimento. Casa Editrice Dott. Eugenio Jovene, Napoli,

Pinto, Carlos Alberto da Mota. Cessão de Contrato. Saraiva, São Paulo, 1.985.

Pontes de Miranda, Francisco Cavalcanti. Tratado de Direito Privado, vol. 38. Borsoi, Rio de Janeiro, 1.962

Proença, José Carlos Brandão. A Resolusão do Contrato no Direito Civil, in Boletim da Faculdade de Direito da Universidade de Coimbra, suplto XXII, 1.975.

Raiser, Ludwig. O Futuro do Direito Privado, in Revista da Procuradoria Geral do Estado - RS, vol. 9, no 25, Porto Alegre, 1.979.

Revista de Jurisprudência do T.J.R.G.S., $\mathrm{n}^{\circ} 133$, Porto Alegre, abril de 1.989 , pp. 343 e ss.

-..., nº 145, Porto Alegre, abril de 1.991, pp. 219 e ss. Ruling Case Law, vol. 6. The Laweyers Co-operative Publisshing Co., New York, 1.915.

Spallarossa, M. Rosa. Importanza dell'Inadempimento e Risaluzione del Contratto, in Rivista di Diritto Civile, ano XVIII, $\mathrm{n}^{\mathrm{O}} 3,1.972$, parte II.

Uda, Giovanni Maria. Integrazione del Contratto, Solida rietá Sociale e Corrispettività delle Prestazion, in Rivista di Diritto Commerciale, gr. $4^{\circ}$, nº 5-6, maio-junho de 1.990.

Vitucci, Paolo. "Ogni Ritardo sará Cosiderato di Scarsa Importanza" (Ipotesi sul Patto di Evitanda Risoluzione), in Rivista di Diritto Civile, ano XXXIV, no 5, setembro-outubro de 1.988 .

Wieacker, Franz. El Principio General de la Buena Fe. Civitas, Madrid, 1.977.

Zana, Mario. La Regola della Buona Fede nell Eccezione di Inadempimento in Rivists Trimestrale di Diritto e Procedura Civile, ano XXVI, no 3, setembro de 1.972. 